\section{THU0256 RISK OF LONG-TERM INCIDENT CARDIOVASCULAR EVENT AND MORTALITY IN PATIENTS WITH SLE AND POPULATION CONTROLS IS ASSOCIATED WITH A HIGHER CAROTID INTIMA-MEDIA THICKNESS}

Sofia Ajeganova ${ }^{1,2}$, Ingiäld Hafström ${ }^{1}$, Johan Frostegård' ${ }^{1}{ }^{1}$ Karolinska Institutet, Stockholm, Sweden; ${ }^{2}$ Vrije Universiteit Brussel, Brussels, Belgium

Background: Measurement of carotid intima-media thickness (cIMT) is promoted as one of the tools for cardiovascular (CV) risk assessment in primary prevention in general population. The diagnosis of systemic lupus erythematosus (SLE) is a strong risk factor for premature CV events and mortality. Whether assessment of CIMT has a value for prediction of $\mathrm{CV}$ morbidity and mortality in patients with SLE compared with population controls of similar age and sex is not established.

Objectives: To examine association of CIMT with risk of incident CV events and mortality in SLE and controls.

Methods: We used the cross-sectional SLEVIC (SLE vascular impact cohort study) cohort of consecutive patients with SLE aged $<70$ years who were regularly treated in a tertiary referral rheumatology center. Carotid ultrasound was performed at inclusion to the cohort (from September 2006 to January 2008) in 118 patients and in 122 population controls matched by age and sex. Incident CV events were defined as hospitalization for angina pectoris, myocardial infarction, bypass grafting, percutaneous coronary or peripheral artery intervention, ischemic stroke and TIA Combined outcome of incident CV event and all-cause mortality was evaluated for a mean (SD) follow-up of 9.6 (1.5) years. Participants with prevalent $\mathrm{CV}$ before inclusion, $\mathrm{n}=18$, and those who were lost to followup, $n=14$, were excluded from this analysis.

Event-free survival rates in patients and controls were compared using Kaplan-Meier curves. Relative hazard ratios from Cox proportional-hazards regression models were used to estimate the effect of cIMT measurement on the outcome.

Results: At inclusion, mean age (SD) of the included 99 patients was 47 (13) years, $87 \%$ females, mean disease duration 12 (9) years, SLEDA 4.0, and SLICC/ACR 1.0. Mean age of included 109 controls was 49 (12) years, $91 \%$ females.

Baseline mean (SD) cIMT did not differ between the groups $(p=0.345)$ and was 607 (127) $\mu \mathrm{m}$ in patients and 623 (118) $\mu \mathrm{m}$ in controls.

During follow-up, 12 patients and 4 controls were defined with the outcome. The outcome was reached more often in patients than in controls, $\mathrm{p}=0.022$. The mean time to outcome (SD) was 9.9 (0.2) years for patients and $10.3(0.1)$ years for controls.

The hazard rate (HR) for the combined outcome of $\mathrm{CV}$ event and mortality was 3.7 -fold $(95 \% \mathrm{Cl}, 1.2-11.5)$ higher in patients than in controls, adjusted for age, sex and smoking history, $\mathrm{p}=0.025$. A higher baseline mean CIMT was significantly associated with the outcome, HR $1.0(95 \%$ $\mathrm{Cl}$, 1.0-1.01) per $1.0 \mu \mathrm{m}$ increase in cIMT, $\mathrm{p}=0.040$, irrespective of the group. Additional adjustment for traditional risk factors, disease duration, treatments, presence of anti-phospholipid antibodies and defining with carotid plaque yielded similar risk estimates.

Conclusion: In this analysis we confirm an elevated long-term risk of important adverse clinical events in patients with SLE compared with controls. A measure of CIMT is associated with incident CV event and mortality. This suggests that assessment with carotid ultrasound may have a value for CV risk stratification and would encourage validation in largecohort prospective populations.

Disclosure of Inter: Sofia Ajeganova: None declared, Ingiäld Hafström: None declared, Johan Frostegård Shareholder of: Minor shareholder and inventor in startup-company Athera Biotechnologies, but they do not produce drugs yet and rheumatology is not in their focus.

DOI: 10.1136/annrheumdis-2019-eular.5763

\section{THU0257}

DIAGNOSTIC PERFORMANCE OF 2002 AECG, 2012 ACR AND 2016ACR/EULAR CLASSIFICATION CRITERIA FOR SJÖGREN'S SYNDROME IN A HISPANIC POPULATION

Nicolás Alfaro ${ }^{1}$, Janett Carmen Riegatorres ${ }^{1}$, Cesar Vidal Solis ${ }^{1}$, David Vega Morales ${ }^{1}$, Brenda Roxana Vázquez Fuentes ${ }^{1}$, Mario Alberto Garza Elizondo ${ }^{1}$, Cassandra Michele Skinner Taylor ${ }^{1}$, Dionicio Ángel Galarza-Delgado ${ }^{1}$ Jesús Mohamed Noriega ${ }^{2}$, Karim Mohamed Noriega ${ }^{2} .{ }^{1}$ Hospital Universitario Dr. José Eleuterio Gonzalez, Department of Rheumatology and Clinical Immunology, Monterrey, Nuevo León, Mexico; ${ }^{2}$ Hospital Universitario Dr. José Eleuterio Gonzalez, Department of Ophthalmology, Monterrey, Nuevo León, Mexico

Background: Primary Sjögren's syndrome (pSS) has several classification criteria, whose diagnostic performances vary depending on the studied population ${ }^{1}$. Concordance and differences among these criterias should be evaluated for independent populations to determine the diagnostic performance.

Objectives: To compare the performance among 3 classification criteria for pSS and determine the level of concordance among them.

Methods: Descriptive, retrospective, and cross-sectional study including 172 patients from the Rheumatology Service of the Hospital Universitario "Dr. José Eleuterio González", who were studied for dry syndrome. The clinical criterion of the attending physician was considered as the gold standard for diagnosis. Different parameters were collected: presence of xerostomia, xerophthalmia, Schirmer's test, sialometry, ocular staining ANA, anti-Ro/SSA and anti-La/SSB antibodies, RF isotypes (IgA, IgM, $\operatorname{lgG}$ ), and focal lymphocytic infiltrate in minor salivary gland biopsy. The criteria proposed by the American European Consensus Group (AECG), $A C R$ and, ACR/EULAR were used to evaluate the classification. Compliance was determined for each set of criteria.

Results: Sociodemographic characteristics and clinical manifestations are shown in Table 1. For the AECG, ACR, and ACR/EULAR criteria, the sensitivity was $89.1 \%, 98.9 \%$ and $88 \%$ and the specificity was $93.8 \%$, $71.3 \%$, and $96.3 \%$, respectively (Table 2 ). The ACR/EULAR criteria have an adequate level of agreement $(\mathrm{k}=0.663, \quad P<0.001)$ with those of the AECG and with respect to the ACR criteria a moderate level of agreement $(\mathrm{k}=0.561, P<0.001)$.

Abstract THU0257 - Table 1. Clinical characteristics.

\begin{tabular}{|c|c|c|c|}
\hline & $\mathrm{pSS}^{*} \mathrm{n}=92$ & $\begin{array}{l}\text { Dry Syndrome } \\
\mathrm{n}=80\end{array}$ & $P$ \\
\hline Age, Median (IQR) & $53[47-64]$ & $51[43-59]$ & 0.214 \\
\hline Female, n (\%) & $89(97 \%)$ & $74(93 \%)$ & 0.213 \\
\hline Xerostomia, n (\%) & $\begin{array}{l}77 / 90 \\
(86 \%)\end{array}$ & $52 / 71(73.2 \%)$ & 0.052 \\
\hline xerophthalmia, n (\%) & $\begin{array}{l}79 / 89 \\
(89 \%)\end{array}$ & $58 / 69(84 \%)$ & 0.307 \\
\hline Schirmer test, $\mathrm{n}(\%)$ & $63(68 \%)$ & $36(45 \%)$ & 0.002 \\
\hline OSS $\geq 3, \mathrm{n}(\%)$ & $60(65 \%)$ & $18(22 \%)$ & $<0.001$ \\
\hline OSS $\geq 5, \mathrm{n}(\%)$ & $\begin{array}{l}59 / 91 \\
(64 \%)\end{array}$ & $11 / 56(19 \%)$ & $<0.001$ \\
\hline USF $<1.5 \mathrm{ml} / 15 \mathrm{~min}, \mathrm{n}(\%)$ & $74(80 \%)$ & $35(43.8 \%)$ & $<0.001$ \\
\hline USF $\leq 0.1 \mathrm{ml} / \mathrm{min}, \mathrm{n}(\%)$ & $76(83 \%)$ & $35(43.8 \%)$ & $<0.001$ \\
\hline $\begin{array}{l}\text { Minor Salivary Gland, } n \\
(\%)\end{array}$ & $\begin{array}{l}73 / 85 \\
(86 \%)\end{array}$ & $23 / 67(34.5 \%)$ & $<0.001$ \\
\hline Anti-Ro/SSA, n (\%) & $70 / 90(78 \%)$ & $5 / 69(7 \%)$ & $<0.001$ \\
\hline Anti-La/SSB, n (\%) & $27 / 86(31 \%)$ & $1 / 65(2 \%)$ & $<0.001$ \\
\hline ANA, $n(\%)$ & $\begin{array}{l}62 / 88 \\
(65 \%)\end{array}$ & $23 / 66(35 \%)$ & $<0.001$ \\
\hline Rheumatoid Factor, n (\%) & $\begin{array}{l}51 / 88 \\
(58 \%)\end{array}$ & $24 / 66(36 \%)$ & 0.008 \\
\hline $\operatorname{lgG}, \mathrm{n}(\%)$ & $\begin{array}{l}17 / 86 \\
(20 \%)\end{array}$ & $7 / 67(10 \%)$ & 0.116 \\
\hline $\lg M, n(\%)$ & $\begin{array}{l}50 / 85 \\
(59 \%)\end{array}$ & $23 / 63(36 \%)$ & 0.017 \\
\hline $\lg A, n(\%)$ & $\begin{array}{l}34 / 83 \\
(41 \%) \\
\end{array}$ & $8 / 63(13 \%)$ & 0.001 \\
\hline
\end{tabular}

OSS: Ocular Staining Score; USF: unstimulated salivary flow.

* The diagnosis of primary Sjögren's Syndrome was made based on clinical criteria ${ }^{\wedge} \mathrm{P}<0.001$

Abstract THU0257 - Table 2. Diagnostic criteria performance.

\begin{tabular}{lccc}
\hline & \multicolumn{3}{c}{ Kappa Cohen } \\
\hline Sensitivity & 2012 & 2016 \\
\hline 2002 AECG & $89.10 \%$ & $0.545^{\wedge}$ & $0.663^{\wedge}$
\end{tabular}


2012 ACR

2016 ACR/

$98.90 \%$

$88.00 \%$

0.561

Specificity

2002 AECG

2012 ACR

2016 ACR/

$93.80 \%$

$71.30 \%$

$96.30 \%$

EULAR

between involvement and atherosclerotic stroke (OR 10.4, 95\% C 2.8-38.5), ear disease (OR 2.1, 95\% Cl 1.1-4.2) and myopathy (OR 6.5, $95 \% \mathrm{Cl} 1.3-31,6)$. Patients with NS involvement had higher probability of being treated with glucocorticoids (OR $3.3,95 \% \mathrm{Cl} 1.5-7.2$ ) and cyclophosphamide (OR 6.8, 95\% Cl 1.5-31).

Conclusion: $15 \%$ of patients with pSS develope NS involvement that is associated with atherosclerotic stroke, ear disease and myopathy.

REFERENCE:

[1] Vitali C. et al. Ann Rheum Dis 2002; 61:554

AECG: American European Consensus Group criteria;

Conclusion: In our population, the ACR criteria showed the highest sensitivity, while the ACR/EULAR criteria showed the highest specificity, showing a moderate level of agreement. Despite the validation of these criteria, its application in real life tests its performance according to the population studied.

\section{REFERENCES:}

[1] Tsuboi, H., et al. (2017). Comparison of performance of the 2016 ACREULAR classification criteria for primary Sjögren's syndrome with other sets of criteria in Japanese patients. Annals of the Rheumatic Diseases, 76(12), 1980?1985. https://doi.org/10.1136/annrheumdis-2016-210758.

Disclosure of Interests: None declared

DOI: 10.1136/annrheumdis-2019-eular.6626

\section{THU0258 NERVOUS SYSTEM INVOLVEMENT IN PRIMARY SJÖGREN'S SYNDROME}

Jose Luis Andreu ${ }^{1}$, Carlos Sánchez-Piedra ${ }^{2}$, Monica Fernandez Castro ${ }^{1}$, Victor Martinez Taboada ${ }^{3}$, Alejandro Olive ${ }^{4}$, Jose Rosas ${ }^{5}$, Raúl Menor-Almagro ${ }^{6}$, Beatriz Rodriguez Lozano ${ }^{7}$, Ángel García-Aparicio ${ }^{8}$, Francisco J López-Longo ${ }^{9}$, Sara Manrique Arija ${ }^{10}$, Jesús Alberto García Vadillo ${ }^{11}$, Susana Gil ${ }^{12}$, Ruth López González ${ }^{13}$, J. Narváez ${ }^{14}$, Carles Galisteo ${ }^{15}$, Jorge Juan Gonzalez Martin ${ }^{16}$, M E Ruiz ${ }^{17}$, Iñigo Rúa-Figueroa ${ }^{18}$, Oscar Illera ${ }^{19}$, Lurdes Romani ${ }^{20}$, Sheila Melchor ${ }^{21}$, Begoña Moreira ${ }^{22}$, Enrique Raya ${ }^{23}$, Jose M Pego-Reigosa ${ }^{24}$, Natalia Cid Boza ${ }^{25}$, Enrique Judez ${ }^{26}$, Clara Moriano ${ }^{27}$, Vicente Torrente ${ }^{28}$, Héctor Corominas ${ }^{29}$, Blanca Garcia-Magallon ${ }^{30}$, Carlos Guillén-Astete ${ }^{31}$, Ivan Castellví ${ }^{32}$, Cristina Bohórquez ${ }^{33}$, Javier Loricera ${ }^{34}$, Joaquín Belzuneguii ${ }^{35} .{ }^{1} \mathrm{H}$. U. Puerta de Hierro Majadahonda, Majadahonda, Spain; ${ }^{2}$ Sociedad Española de Reumatología, Madrid, Spain; ${ }^{3}$ H.U. Marqués de Valdeilla, Santander, Spain; ${ }^{4}$ H.U. Germans Trias i Pujol, Badalona, Spain; ${ }^{5}$ H.U. Marina Baixa, Villajoyosa, Spain; ${ }^{6}$ H.U. Jerez de la Frontera, Jerez de la Frontera, Spain; ${ }^{7}$ H.U. de Canarias, Santa Cruz de Tenerife, Spain; ${ }^{8}$ H.U. Virgen de la Salud, Toledo, Spain; ${ }^{9}$ H.G.U. Gregorio Marañón, Madrid, Spain; ${ }^{10}$ H.U. Carlos Haya, Málaga, Spain; ${ }^{11}$ H.U. La Princesa, Madrid, Spain; ${ }^{12}$ H.U. de Alicante, Alicante, Spain; ${ }^{13}$ H.U. Virgen de la Concha, Zamora, Spain; ${ }^{14}$ H.U. Bellvitge, Barcelona, Spain; ${ }^{15}$ H.U. Parc Tauli, Sabadell, Spain; ${ }^{16}$ H.U. Madrid Norte Sanchinarro, Madrid, Spain; ${ }^{17}$ H.U. Basurto, Bilbao, Spain; ${ }^{18}$ H.U. Doctor Negrín, Las Palmas, Spain; ${ }^{19}$ H.U. Infanta Sofía, San Sebastián de los Reyes, Spain; ${ }^{20} \mathrm{H}$.U. Virgen de las Nieves, Granada, Spain; ${ }^{21} \mathrm{H}$. U. 12 de Octubre, Madrid, Spain; ${ }^{22}$ H.U. Sierrallana, Sierrallana, Spain; ${ }^{23}$ H.U. San Cecilio, Granada, Spain; ${ }^{24}$ H.U. do Mexoeiro, Vigo, Spain; ${ }^{25}$ H.U. Valme, Sevilla, Spain; ${ }^{26}$ H.U. de Albacete, Albacete, Spain; ${ }^{27}$ C.A.H. de Leon, Leon, Spain; ${ }^{28}$ H.U. L'Hospitalet, Barcelona, Spain; ${ }^{29}$ H.U. Sant Joan Despí Moisès Broggi, Barcelona, Spain; ${ }^{30}$ H.U. Miguel Servet, Zaragoza, Spain; ${ }^{31}$ H.U. Ramón y Cajal, Madrid, Spain; ${ }^{32}$ H.U. Santa Creu i Sant Pau, Barcelona, Spain; ${ }^{33}$ H.U. Príncipe de Asturias, Madrid, Spain; ${ }^{34}$ H. U. Marqués de Valdecilla, Santander, Spain; ${ }^{35}$ H.U. Donostia, San Sebastián, Spain

Background: Primary Sjögren's syndrome (pSS) is a systemic autoimmune disease characterized by the involvement of the exocrine glands, mainly salivary and lacrimal glands. Approximately half of patients will experience extraglandular complications throughout their evolution.

Objectives: To characterize the involvement of the nervous system (NS) in patients with pSS.

Methods: Multicenter cross-sectional study of a cohort of patients with pSS, constructed by random selection of pSS patients fulfilling the 2002 American-European Consensus Criteria for $\mathrm{pSS}^{1}$ from 33 rheumatology units. Through review of clinical records and interview with patients, demographic, clinical, analytical, therapeutic data and disease activity indexes were collected. Univariate analysis was done by Chi square test, MannWhitney $U$ test and Student's $t$ test. Multivariate analysis was done by linear logistic regression. A $p<0.05$ was considered significant. Patients signed an informed consent. The study was authorized by the ethics committees.

Results: 437 patients were included (95\% women, median age of 58 years). 65 patients developed NS involvement: 26 patients central NS, 31 peripheral NS and 8 both. Multivariate analysis showed association

Disclosure of Interests: Jose Luis Andreu: None declared, Carlos Sánchez-Piedra: None declared, Monica Fernandez Castro: None declared, Victor Martinez Taboada: None declared, Alejandro Olive: None declared, Jose Rosas Consultant for: Abbvie, Amgen, Bristol, Janssen, Lilly, Merck Sharp \& Dohme, Pfizer, UCB Pharma, Speakers bureau: Abbvie, Amgen, Bristol, Janssen, Lilly, Merck Sharp \& Dohme, Pfizer, UCB Pharma, Raúl Menor-Almagro: None declared, Beatriz Rodriguez Lozano: None declared, Ángel García-Aparicio: None declared, Francisco J López-Longo: None declared, Sara Manrique Arija Speakers bureau: ABBvie, MSD, Janssen, Lilly, Roche, Pfyzer, Novartis., Jesús ALberto García Vadillo: None declared, Susana Gil: None declared, Ruth López González: None declared, J. Narváez Consultant for: Bristol-Myers Squibb, Carles Galisteo: None declared, Jorge Juan Gonzalez Martin: None declared, M E Ruiz: None declared, Iñigo Rúa-Figueroa: None declared, Oscar Illera: None declared, Lurdes Romani: None declared, Sheila Melchor: None declared, Begoña Moreira: None declared, Enrique Raya: None declared, Jose M Pego-Reigosa: None declared, Natalia Cid Boza: None declared, Enrique Judez: None declared, Clara Moriano: None declared, Vicente Torrente: None declared, Héctor Corominas: None declared, Blanca Garcia-MagalIon: None declared, Carlos Guillén-Astete: None declared, Ivan Castellví Consultant for: I received fees less than 5000USD as a consultant for Kern and Actelion, Paid instructor for: I received fees less than 2000USD as a instructor for Boehringer -Ingelheim, Novartis and Gebro, Speakers bureau: ND, Cristina Bohórquez: None declared, Javier Loricera: None declared, Joaquín Belzunegui: None declared

DOI: 10.1136/annrheumdis-2019-eular.3607

\section{THU0259 \\ ULTRASOUND OF MAJOR SALIVARY GLANDS IDENTIFIES PATIENTS WITH MORE COMPLEX SALIVARY GLAND HISTOPATHOLOGY BUT NOT MILDER LESIONS}

Chiara Baldini ${ }^{1}$, Francesco Ferro ${ }^{1}$, Nicoletta Luciano ${ }^{1}$, Gianmaria Governato ${ }^{1}$, Marta Mosca ${ }^{1}$, Stefano Bombardieri ${ }^{1}$, Valentina Donati ${ }^{2} .{ }^{1}$ University of Pisa, Department of Clinical and Experimental Medicine, Pisa, Italy; ${ }^{2}$ University of Pisa, Pathology Unit, Pisa, Italy

Background: Ultrasonography of major salivary glands (SGUS) has been proposed as a feasible and reliable tool for the assessment of parotid and submandibular glands inflammation and damage in Sjögren's syndrome (pSS). However, the relationship between major SGUS and labial salivary gland (LSG) histopathology is still unclear.

Objectives: to investigate the correlation between SGUS abnormalities and LSG histopathology in patients newly diagnosed patients with pSS

Methods: Consecutive patients suspected of having pSS were enrolled in this study. All the patients underwent a complete diagnostic work up. The echostructure of each gland on B-mode images was graded on a 5 point scale (0-4), and a SGUS score $\geq 2$ was defined as pathological. Hypo-anechoic areas in the glands were defined as isolated $(<25 \%$ of the surface), localized $(25-50 \%)$ and diffuse-scattered (>50\%). Hyperechoic bands present in more than $50 \%$ of the parenchyma were also recorded. An expert pathologist analyzed all the LGS samples assessing focus score (FS), number of foci and presence of ectopic germinal centers (GCs).

Results: We included 115 pts (105 F: 10 M, mean age (SD) 54.8 (12.5) years). Out of them 51 were diagnosed with pSS and 64 represented the no-SS sicca controls. A SGUS score $\geq 2$ identified pSS patients with a sensitivity of $62.7 \%$ and a specificity of $96.7 \%$. SGUS score significantly correlated with FS $\left(r=0.457^{* *}, p=0.000\right)$, number of foci $\left(r=0.359^{* *}\right.$, $\mathrm{p}=0.000)$ and number of ectopic GCs $\left(r=0.505^{* *}, \mathrm{p}=0.000\right)$. However, the overall concordance between SGUS and LSG histopathology was moderate (Cohen's kappa $=0.574$ ). Thus, we specifically focused on 19/51 pSS "discordant" cases who presented normal SGUS findings but focal lymphocytic sialadenitis in their LSG biopsy. These "discordant" patients tended to present a lower FS $(1.7 \pm 0.5$ vs $2.6 \pm 1.5, \mathrm{p}=0.04)$ and a significantly lower number of foci in their biopsies $(2.7 \pm 1.6$ vs $4.6 \pm 2.9$, 